\title{
Nanowire Fabrication in Porous Alumina Tempalets Produced by Employing Sulphuric, Oxalic and Phosphoric Acids
}

\author{
Ramakrishna Kotha', Diana Strickland ${ }^{2}$, Arturo A. Ayon ${ }^{1}$ \\ ${ }^{1}$ MEMS Research Lab, Department of Physics \& Astronomy, University of Texas San Antonio, \\ San Antonio, TX, USA \\ ${ }^{2}$ Applied Physics Division, Southwest Research Institute, San Antonio, TX, USA \\ Email: kotha.rama@gmail.com
}

Received 1 June 2015; accepted 20 July 2015; published 23 July 2015

Copyright (C) 2015 by authors and Scientific Research Publishing Inc.

This work is licensed under the Creative Commons Attribution International License (CC BY). http://creativecommons.org/licenses/by/4.0/

(c) (i) Open Access

\begin{abstract}
We report the growth of silver nanowires with varying diameters in porous anodic aluminumoxide (AAO) membranes by using the electroless deposition approach. This objective is carried out in 2 phases. In Phase 1, AAO membranes on high purity aluminum foils are electrochemically grown by a double anodization procedure. Three different electrolytes, sulphuric acid $\left(\mathrm{H}_{2} \mathrm{SO}_{4}\right)$, oxalic acid $\left(\mathrm{H}_{2} \mathrm{C}_{2} \mathrm{O}_{4}\right)$ and phosphoric acid $\left(\mathrm{H}_{3} \mathrm{PO}_{4}\right)$, are employed to produce membranes with varying pore diameters. Other parameters such as interpore distance, barrier layer thickness and membrane thickness are also explored. In addition, characterization to modify the pore diameter and open the barrier layer of free standing AAO templates has been carried out. In Phase 2, metallic silver nanowires are grown by electroless deposition inside pores with varying diameters in AAO membranes. AAO membranes immersed in aqueous silver nitrate solutions are thermally reduced, and the resulting silver nanowires are characterized by using a scanning electron microscope (SEM).
\end{abstract}

\section{Keywords}

Anodic Aluminum Oxide, Electroless Deposition, Silver Nanowires, Barrier Layer

\section{Introduction}

Anodic aluminum-oxide membranes have been widely studied due to their numerous advantages in the manu-

How to cite this paper: Kotha, R., Strickland, D. and Ayon, A.A. (2015) Nanowire Fabrication in Porous Alumina Tempalets Produced by Employing Sulphuric, Oxalic and Phosphoric Acids. Open Journal of Inorganic Non-Metallic Materials, 5, 41-49. http://dx.doi.org/10.4236/ojinm.2015.53005 
facturing of micro and nanoscale devices for applications in fields such as optics, electronics, and optoelectronics. Nanowires [1], nanotubes [2], nanorods [3], and nanodots [4] have been grown or fabricated in patterns for use in nanoscale devices using AAO membranes as templates. In particular, nanowires grown in AAO templates have received significant attention for their use in scientific applications such as information storage [5] and nanolenses [6].

The simplest and most inexpensive approach to growing AAO membranes is by a double anodization procedure in which aqueous electrolyte solutions such as sulphuric, oxalic, or phosphoric acid oxidize and pattern an aluminum foil [7]-[11]. Critical parameters such as interpore distance, pore diameter, barrier layer thickness and membrane thickness are changed by varying electrolyte concentration, voltage, growth time and temperature. Fabrication of nanowires within the AAO membranes by techniques such as electrodeposition [12] [13], electroplating [1] and electroless deposition [14] has been demonstrated. Silver nanowires are fabricated in the AAO pores by the thermal reduction of a silver nitrate solution bath.

In this article, we extensively map the effects of changing the process parameters on AAO membrane features with through process characterization. We additionally map the process of barrier layer removal and further pore widening. As a result, we find that we can produce nanowire-filled templates with targeted dimensions, useful in lensing applications. The following tasks have been accomplished: (a) AAO template anodization using sulphuric, oxalic and phosphoric acid; (b) pore widening characterization; (c) membrane release and barrier layer opening; and (d) electroless deposition of silver nanowire in AAO membranes.

\section{Experiments}

\subsection{Anodization}

High purity (99.997\%) aluminum foils of 100 micron thickness were employed as anodization substrates. Aluminum foils were cleaned by sonification in subsequent baths of acetone, isopropanol and deionized water solutions for 10 minutes each, then dried with compressed nitrogen. The anodization process was carried out in a two step procedure [10] [15] in each of three different aqueous electrolyte solutions, sulphuric acid $\left(\mathrm{H}_{2} \mathrm{SO}_{4}\right)$, oxalic acid $\left(\mathrm{H}_{2} \mathrm{C}_{2} \mathrm{O}_{4}\right)$ and phosphoric acid $\left(\mathrm{H}_{3} \mathrm{PO}_{4}\right)$. In the first anodization step, the aluminum foil was immersed in an aqueous electrolyte and an oxide layer with aligned pores was grown. This layer is imperfect, but it serves to produce regular patterns of dimple arrays in the aluminum substrate. This first oxide layer was removed by chemical etching with a mixture of $1.8 \mathrm{wt} \%$ chromic acid and $6 \mathrm{wt} \%$ phosphoric acid, exposing the dimples on the aluminum foil. By performing a second anodization, ordered nanochannels were obtained. Both anodizations were conducted in an electrochemical cell under constant cell potential with a lead cathode and a copper anode. The cell was maintained at a low temperature by a refrigerated circulating bath. Porous aluminum-oxide membranes were grown with different electrolyte solutions and conditions as shown in Table 1. Scanning electron micrographs of the top and cross sectional views of as-grown AAO membranes are shown in Figure 1.

\subsection{Pore Widening of AAO Templates}

A subsequent wet etching step on the formed AAO templates allows additional flexibility to increase the diameter of the nanochannels. To explore this option, AAO membranes were immersed in a $5 \mathrm{wt} \%$ phosphoric acid solution maintained at $30^{\circ} \mathrm{C}$. Etch time was varied to determine its effect on the increase of pore diameters. AAO membranes produced using each of the three different electrolyte solutions were tested.

\subsection{Barrier Layer Opening}

In Figures 1(d)-(f) the closed bottom of the AAO nanochannels can be examined. Several applications of AAO require open channels; this can be accomplished either by chemical etching with acidic solutions [16] [17] or by ion beam milling [17] [18]. In this work, we opened the channels with acidic solutions.

In order to retain the as-grown pore morphology of AAO, a protective coating layer is required during the aluminum metal substrate removal and bottom pore opening procedure. As described by Xu et al. [19], commercially available nail polish (Maybelline, Express Finish) was used as a protective coating. These coatings have a similar chemical composition to those used by Masuda et al. [18]. Prior to the aluminum metal removal and the pore opening procedure, the protective coating was applied and allowed to dry at ambient condi- 
Table 1. Operating conditions of different electrolyte solutions for anodic aluminum oxide anodization.

\begin{tabular}{cccc}
\hline Electrolyte & $\mathrm{H}_{2} \mathrm{SO}_{4}$ & $\mathrm{H}_{2} \mathrm{C}_{2} \mathrm{O}_{4}$ & $\mathrm{H}_{3} \mathrm{PO}_{4}$ \\
\hline Conc & $0.3 \mathrm{M}$ & $0.3 \mathrm{M}$ & $0.3 \mathrm{M}$ \\
Voltage & $25 \mathrm{~V}$ & $60 \mathrm{~V}$ & $165 \mathrm{~V}$ \\
Temp. & $0.5^{\circ} \mathrm{C}$ & $1{ }^{\circ} \mathrm{C}$ & $1{ }^{\circ} \mathrm{C}$ \\
$1^{\text {st }}$ Anod. & $480 \mathrm{~min}$ & $240 \mathrm{~min}$ & $60 \mathrm{~min}$ \\
Oxide Removal & 420 min, $60^{\circ} \mathrm{C}$ & $420 \mathrm{~min}, 60^{\circ} \mathrm{C}$ & $420 \mathrm{~min}, 60^{\circ} \mathrm{C}$ \\
$2^{\text {nd }}$ Anod & $480 \mathrm{~min}$ & $240 \mathrm{~min}$ & $240 \mathrm{~min}$ \\
\hline
\end{tabular}

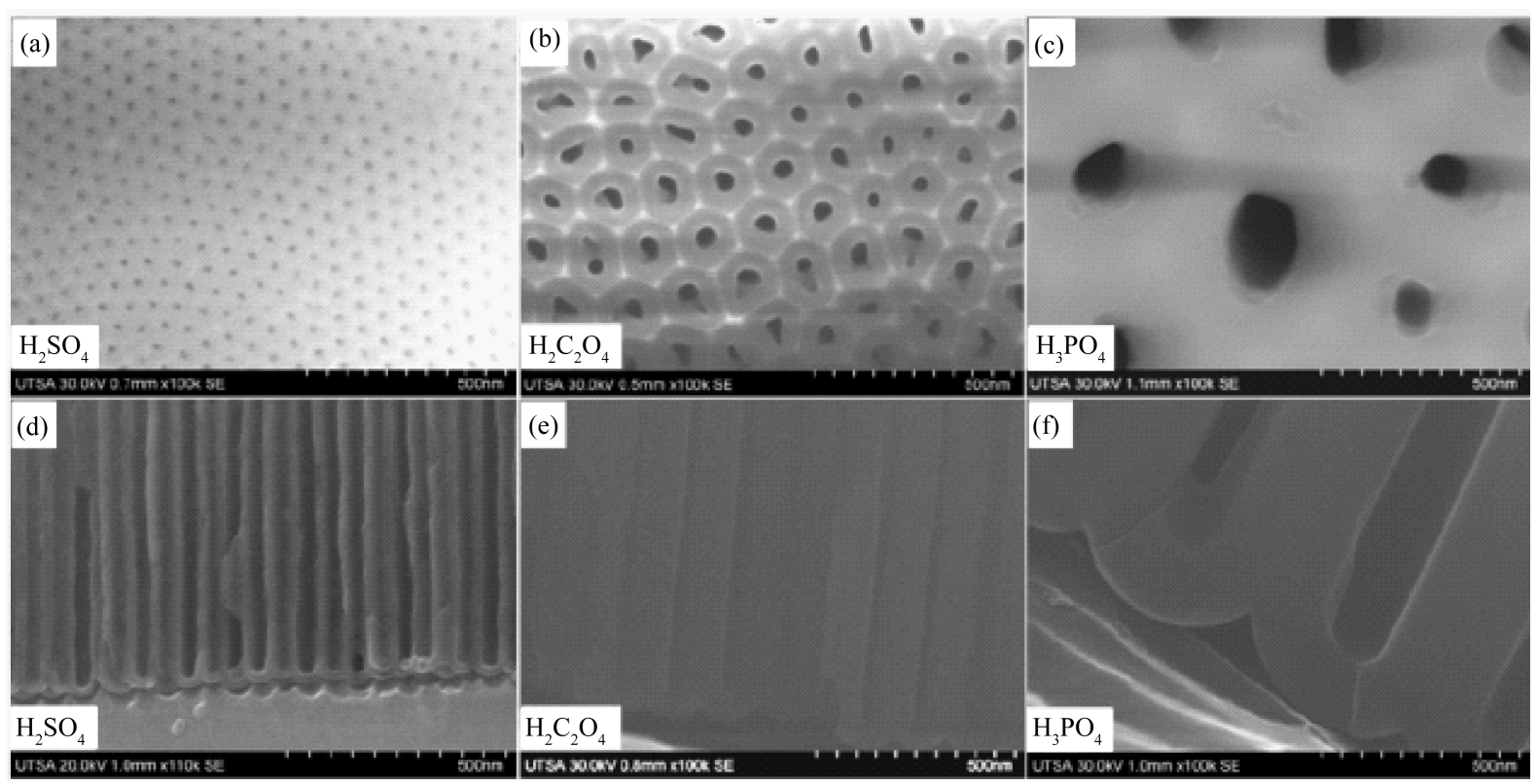

Figure 1. SEM Micrographs of Top view (a), (b), (c) and Cross sectional view (d), (e), (f) of Anodic Aluminum Oxide templates grown with three different electrolytes $\mathrm{H}_{2} \mathrm{SO}_{4}, \mathrm{H}_{2} \mathrm{C}_{2} \mathrm{O}_{4}$, and $\mathrm{H}_{3} \mathrm{PO}_{4}$.

tions. Later the aluminum metal was removed completely with a chemical mixture of tin chloride and deionized water. This etch process was sensitive to process variation and had to be executed according to recipe specifications. The free standing anodic aluminum oxide membranes as shown in Figure 2 were rinsed with deionized water and dried with nitrogen. Note the macroscopic size of the membrane shown in Figure 2. A 5 wt\% phosphoric acid solution was used to open the barrier layer of AAO membranes grown by different electrolyte solutions.

\subsection{Electroless Deposition of Silver}

Electroless deposition of silver nanowires as described by Kim et al. [14] took place in AAO membranes with varying pore diameters. AAO membranes were immersed in $0.1 \mathrm{M}$ aqueous silver nitrate solution at a temperature for 2 hours, forming the silver nanowires by thermal reduction. After a one minute sonification, the nanowires were thermally annealed to a temperature of $350^{\circ} \mathrm{C}$ for $90 \mathrm{~min}$.

\subsection{Inspection}

AAO membranes and silver nanowires were inspected using a scanning electron Microscope (SEM, Hitachi S5500). 


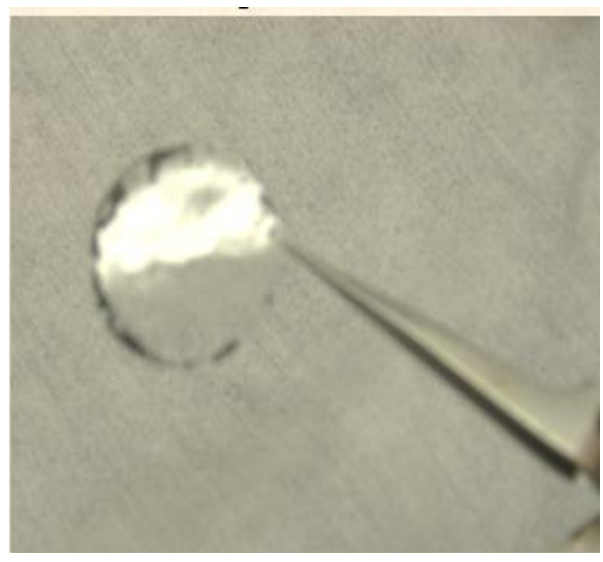

Figure 2. Free standing AAO membrane.

\section{Results \& Discussions}

\subsection{Anodic Aluminumoxide Membranes}

SEM micrographs of the AAO membranes grown by the two step anodization employing three different electrolytes are shown in Figure 1. As shown in Table 2, Pore diameter and interpore distance increased with increasing voltage potential applied for different electrolyte solutions in the following order: $\mathrm{H}_{2} \mathrm{SO}_{4}<\mathrm{H}_{2} \mathrm{C}_{2} \mathrm{O}_{4}<$ $\mathrm{H}_{3} \mathrm{PO}_{4}$. High aspect ratio nanochannels were formed the most quickly in the oxalic solution. The interpore distance in the oxalic acid-formed membranes was of medium size, with the pore diameter occupying a little less than a quarter of the cell. The cells were larger in the membrane formed in phosphoric acid, with a similar diameter to interpore distance ratio. Sulphuric acid-formed templates resulted in the most regular arrays of the smallest cells and pores. In this case the pores occupied about half of the interpore distance. The resulting membranes occupied macroscopically large areas patterned with nanoscopic structures. The results of this step show that all three process methods result in viable, regularly patterned structures. A wide range of interpore distances, between 30 and 500 nanometers, was achieved with the processes.

\subsection{Pore Widening Characterization}

The pore widening characterization of the different AAO membranes at 30, 45, and 60 minute intervals is shown in Figures 3-5. For the sulphuric acid-formed templates, the walls of the pores were beginning to break through at 30 minutes with collapse of much of the structure by 60 minutes. The cell walls of the oxalic acid-formed membranes did not break through during the full 60 minutes, and the phosphoric acid-formed membranes did not come close to breakthrough. These results are consistent with the respectively increasing cell wall thickness in the different types of membranes. With increasing pore size, the regularity and symmetry of the pores' shape increased.

Porosity variation of AAO membranes was calculated as discussed by Nielsch et al. [8]. The highest porosity was achieved for sulphuric acid-anodized membranes, and the 60 minute etch resulted in structural collapse and released alumina fibers as shown in Figure 3(d). High porosity in sulfuric acid-formed membranes is due to its lower wall thickness than the oxalic- and phosphoric acid-formed membranes. These two membranes have lower maximum achieved porosities of $77.87 \%$ and $38.36 \%$ respectively. (Figure 6)

The results of these tests show that pore diameter can be independently increased over a wide range at fixed interpore distances in this post-template formation step.

\subsection{Barrier Layer Opening Characterization}

A thin, dense dielectric layer is formed at the pore bases of the templates during the anodization of aluminum. It has similar characteristics of the native oxide film, and allows the passage of electrical currents only through faults in the structure. The thickness of the barrier layer is dependent on the voltage applied during anodization. Thickness increased in the following order in the given conditions: sulphuric acid $(25 \mathrm{~V})<$ oxalic acid $(60 \mathrm{~V})<$ 
Table 2. Pore Diameter, Interpore Distance and Growth rate parameters for AAO membranes nodized with various electrolytes.

\begin{tabular}{cccc}
\hline Electrolyte & $\mathrm{H}_{2} \mathrm{SO}_{4}$ & $\mathrm{H}_{2} \mathrm{C}_{2} \mathrm{O}_{4}$ & $\mathrm{H}_{3} \mathrm{PO}_{4}$ \\
\hline Pore Diameter & $16 \mathrm{~nm}$ & $33 \mathrm{~nm}$ & $120 \mathrm{~nm}$ \\
Interpoer Distance & $33 \mathrm{~nm}$ & $150 \mathrm{~nm}$ & $515 \mathrm{~nm}$ \\
Growth Rate & $4 \mu \mathrm{m} / \mathrm{hr}$ & $11.63 \mu \mathrm{m} / \mathrm{hr}$ & $1.12 \mu \mathrm{m} / \mathrm{hr}$ \\
\hline
\end{tabular}

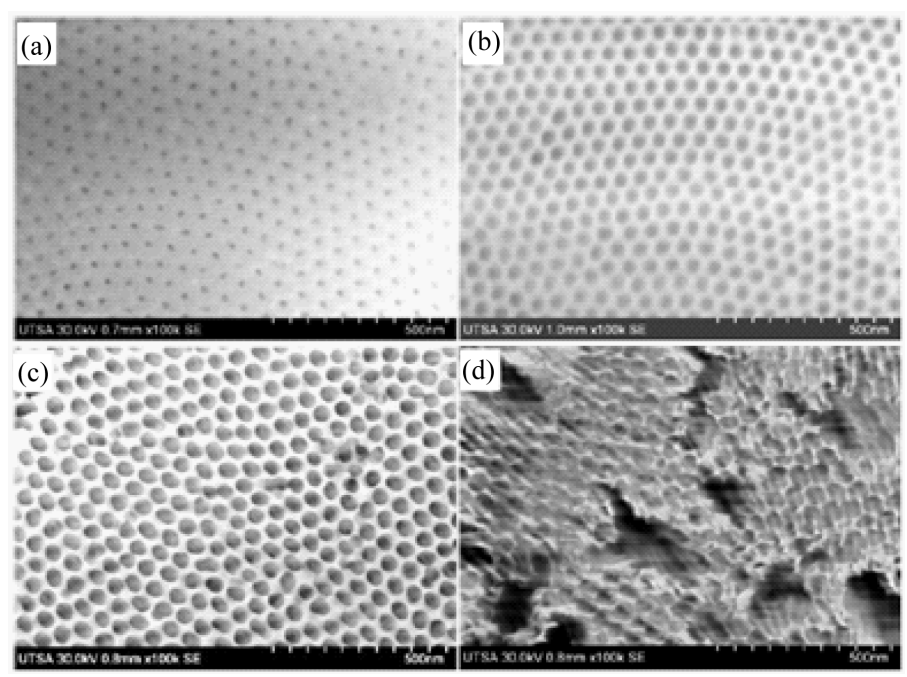

Figure 3. Pore-widening characterization of $\mathrm{H}_{2} \mathrm{SO}_{4}$ grown AAO templates with $5 \mathrm{wt} \%$ Phosphoric Acid. (a) As-grown sample, (b) 30 min etch, (c) 45 min etch, and (d) 60 min etch.
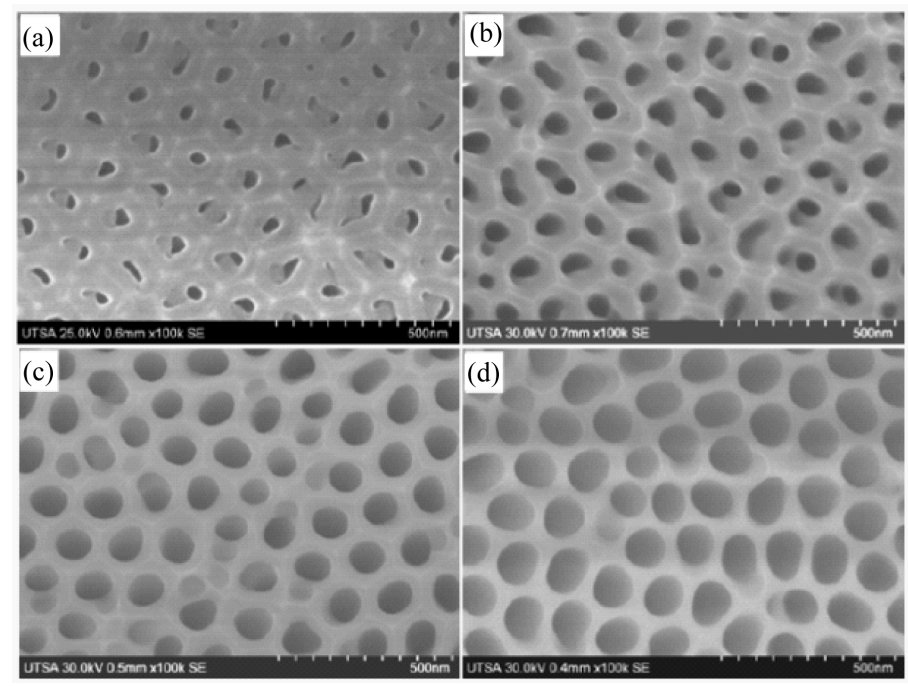

Figure 4. Pore-widening characterization of $\mathrm{H}_{2} \mathrm{C}_{2} \mathrm{O}_{4}$ grown AAO templates with $5 \mathrm{wt} \%$ Phosphoric Acid. (a) As-grown sample, (b) 30 min etch, (c) 45 min etch, and (d) 60 min etch.

phosphoric acid (165 V). In Figures 7-9, the barrier layer is characterized for AAO templates grown with three different electrolytes. Figure 10 illustrates the etch duration required to open the bottom pores of AAO membranes: 30 minutes for $\mathrm{H}_{2} \mathrm{SO}_{4}, 60$ minutes for $\mathrm{H}_{2} \mathrm{C}_{2} \mathrm{O}_{4}$, and 270 minutes for $\mathrm{H}_{3} \mathrm{PO}_{4}$. 


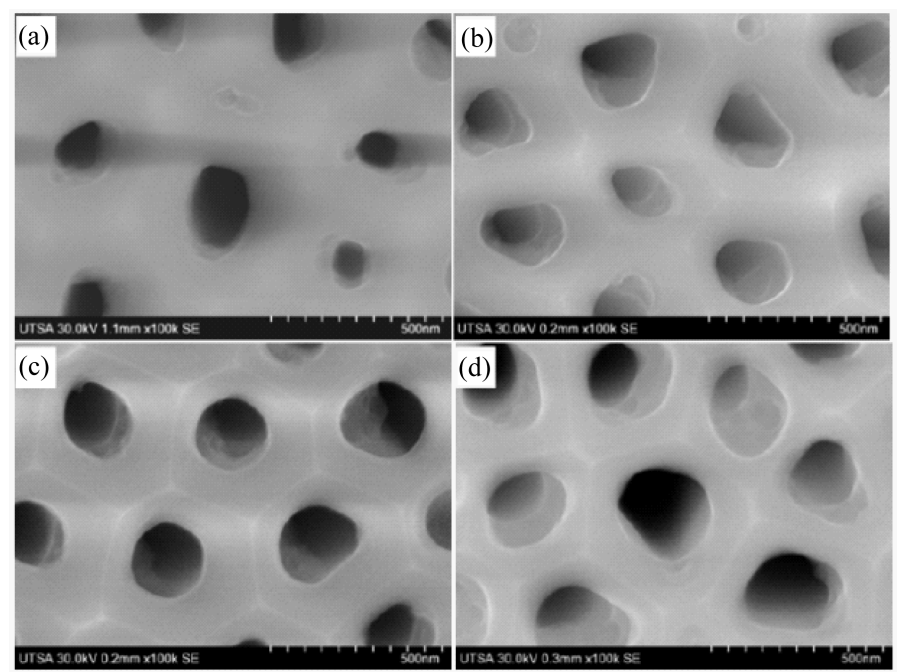

Figure 5. Pore-widening characterization of $\mathrm{H}_{3} \mathrm{PO}_{4}$ grown AAO templates with 5 Wt\% Phosphoric Acid. (a) As-grown sample, (b) 30 min etch, (c) 45 min etch, and (d) 60 min etch.

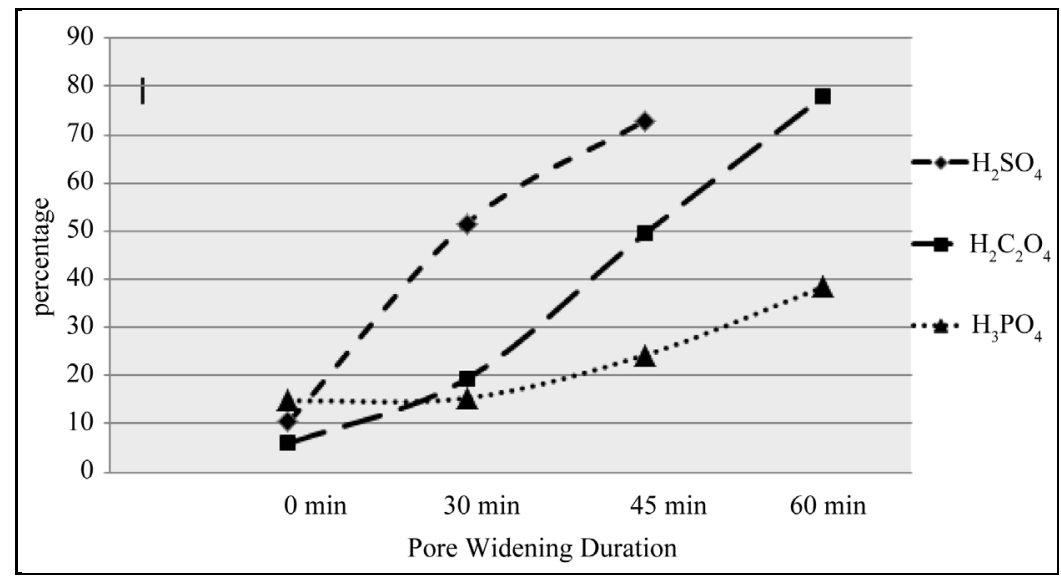

Figure 6. Porosity variation of AAO membranes grown in different electrolyte solutions.
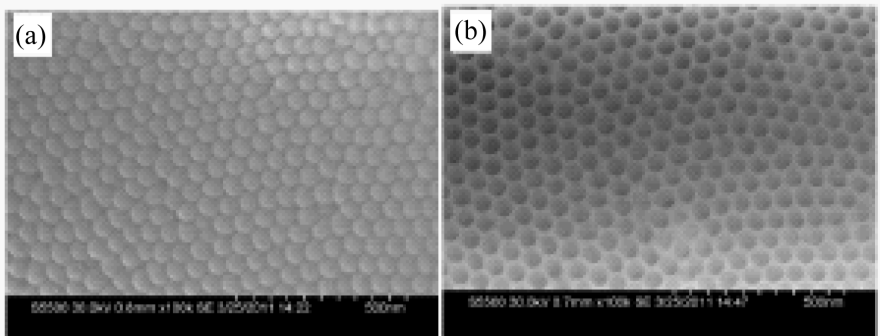

Figure 7. Barrier Layer opening Characterization of $\mathrm{H}_{2} \mathrm{SO}_{4}$ grown AAO templates with 5 wt\% Phosphoric Acid. (a) As-grown sample, (b) 30 min etch.

\subsection{Electroless Deposition of Silver Nanowires in AAO Templates}

In this work, the main focus was to fabricate silver nanowires with varying diameters employing AAO templates. As discussed above, membranes were fabricated with varying pore diameters such as $30 \mathrm{~nm} \mathrm{H}_{2} \mathrm{SO}_{4}, 60 \mathrm{~nm}$ $\mathrm{H}_{2} \mathrm{C}_{2} \mathrm{O}_{4}$, and $200 \mathrm{~nm} \mathrm{H}_{3} \mathrm{PO}_{4}$. As described by Kim et al., silver nanowires were fabricated by electroless depo- 


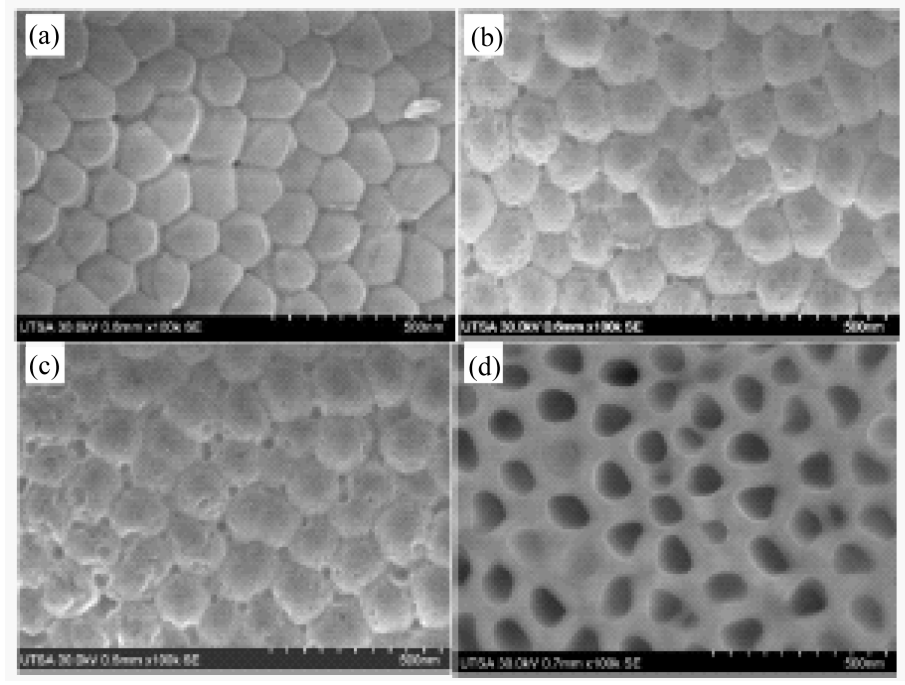

Figure 8. Barrier Layer opening Characterization of $\mathrm{H}_{2} \mathrm{C}_{2} \mathrm{O}_{4}$ grown AAO templates with $5 \mathrm{wt} \%$ Phosphoric Acid. (a) As-grown sample, (b) 30 min etch, (c) 45 min etch, and (d) 60 min etch.

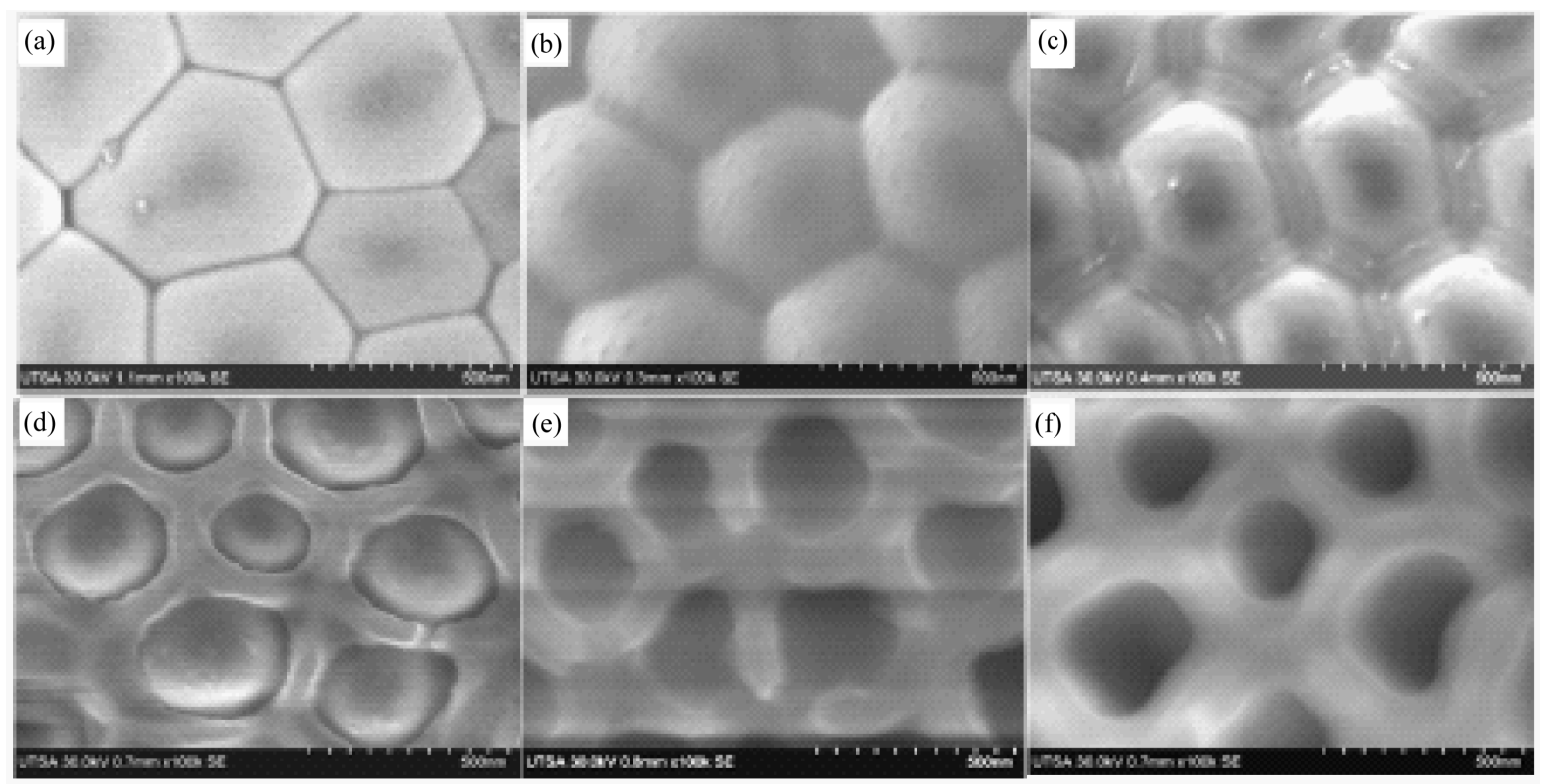

Figure 9. Barrier layer opening characterization of $\mathrm{H}_{3} \mathrm{PO}_{4}$ grown Anodic Aluminum-oxide templates with 5 wt\% Phosphoric Acid. (a) As-grown sample, (b) 90 min etch, (c) 180 min etch, (d) 240 min etch, (e) 270 min etch, and (f) 300 min etch.

sition approach. Silver nanowires (lighter gray) were grown in AAO membranes as shown in Figures 11-13. During the cross-sectioning procedure necessary to attain these images, some wire material was lost. However, the images clearly show that metal wires with high aspect ratios were formed within the pores of all three types of membranes, and that the wires filled the pores.

\section{Conclusion}

In summary, various AAO membrane parameters such as pore diameter, interpore distance and barrier layer thickness were explored with different electrolytes solutions such as sulphuric, oxalic and phosphoric acids. The observed template growth rate was the highest in oxalic acid $(\sim 11.6 \mu \mathrm{m} / \mathrm{hour})$ and lowest in phosphoric acid ( 1.1 $\mu \mathrm{m} /$ hour). In addition, pore widening characterization to alter cell diameter and bottom pore opening characteri- 


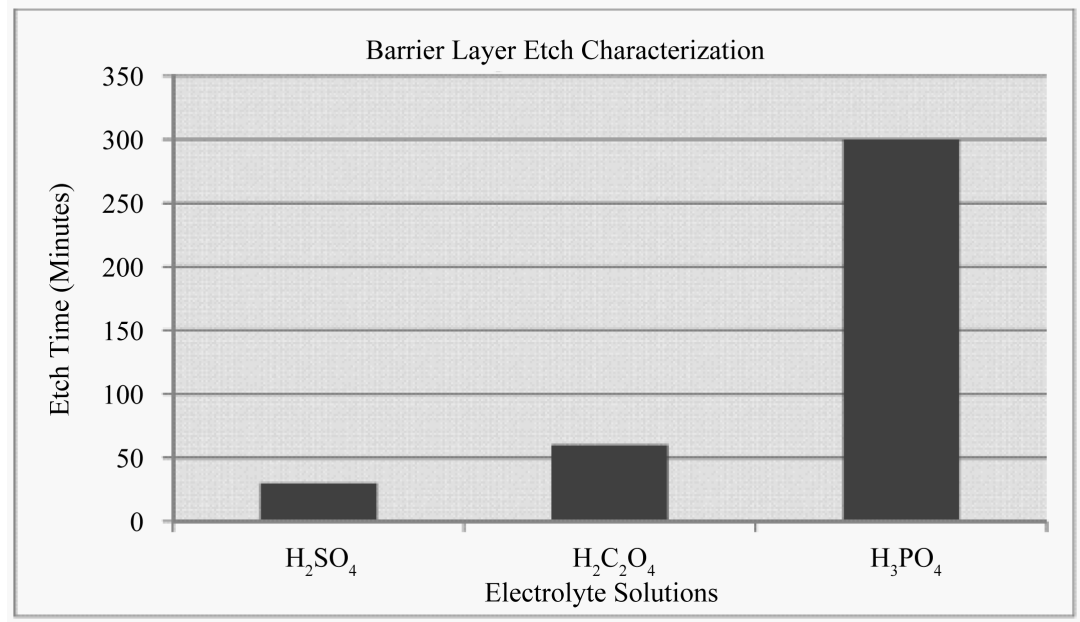

Figure 10. Barrier etch time characterization of AAO membranes.

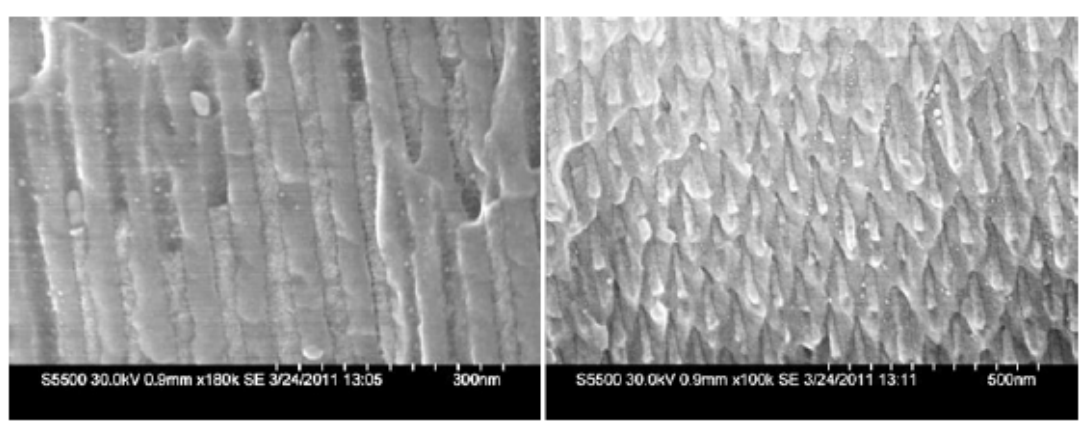

Figure 11. Silver Nanowires grown in $\mathrm{H}_{2} \mathrm{SO}_{4} \mathrm{AAO}$ templates.

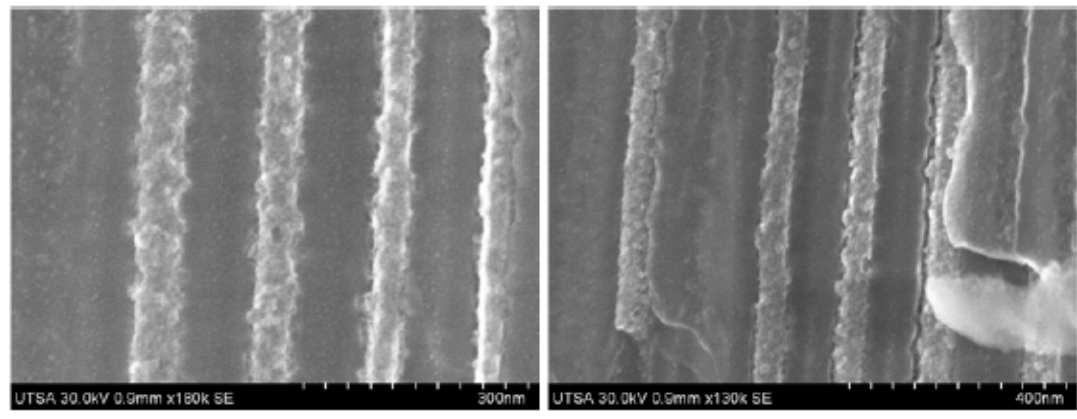

Figure 12. Silver Nanowires grown in $\mathrm{H}_{2} \mathrm{C}_{2} \mathrm{O}_{4} \mathrm{AAO}$ templates.

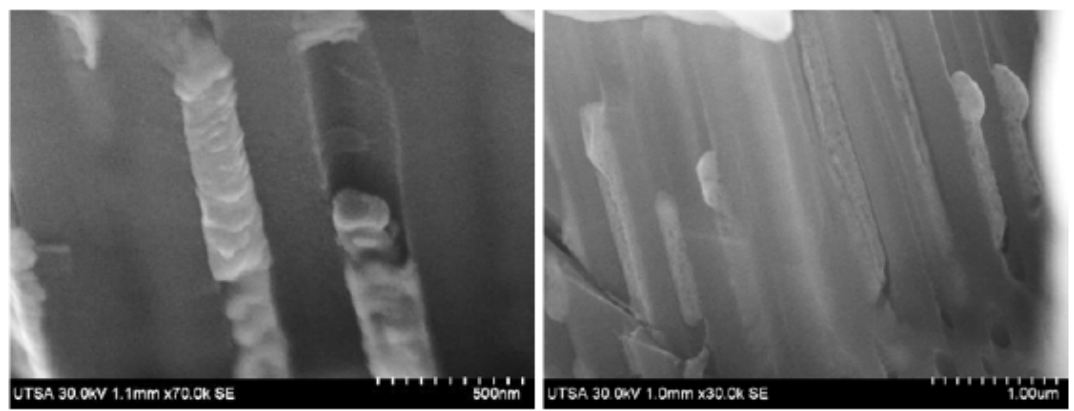

Figure 13. Silver Nanowires grown in $\mathrm{H}_{3} \mathrm{PO}_{4} \mathrm{AAO}$ templates. 
zation free standing AAO membranes has been accomplished by varying the etch duration in diluted phosphoric acid solutions. Electroless deposition of silver nanowires was carried out with silver nitrate solution, and nanowires with varying diameters were fabricated from AAO membranes grown with different electrolytes. We demonstrated that macroscopically large AAO templates with a wide range of controllable parameters could be formed and filled with silver nanowires of high aspect ratios in a relatively inexpensive and simple process.

\section{References}

[1] Jie, F., Cherevko, S. and Chung, C.-H. (2008) Electroplating of Metal Nanotubes and Nanowires in a High Aspect-Ratio Nanotemplate. Electrochemistry Communications, 10, 514-518. http://dx.doi.org/10.1016/j.elecom.2008.01.015

[2] Chu, S.Z., Wada, K., Inoue, S. and Todoroki, S. (2003) Fabrication of Oxide Nanostructures on Glass by Aluminum Anodization and Solgel Process. Surface and Coatings Technology, 169-170, 190-194. http://dx.doi.org/10.1016/S0257-8972(03)00057-4

[3] Moon, J.-M. and Wei, A. (2005) Uniform Gold Nanorod Arrays from Polyethylenimine-Coated Alumina Templates. Journal of Physical Chemistry B, 109, 23336-23341. http://dx.doi.org/10.1021/jp054405n

[4] Chen, P.-L., Kuo, C.-T., Pan, F.-M. and Tsai, T.-G. (2004) Preparation and Phase Transformation of Highly Ordered $\mathrm{TiO}_{2}$ Nanodot Arrays on Sapphire Substrates. Applied Physics Letters, 84, 3888-3890. http://dx.doi.org/10.1063/1.1738941

[5] Juang, J.-Y. and Bogy, D.B. (2005) Nanotechnology Advances and Applications in Information Storage. Microsystem Technologies, 11, 950-957.

[6] Casse, B.D.F., Lu, W.T., Huang, Y.J., Gultepe, E., Menon, L., et al. (2010) Super-Resolution Imaging Using a ThreeDimensional Metamaterials Nanolens. Applied Physics Letters, 96, Article ID: 023114.

[7] Chu, S.Z., Wada, K., Inoue, S., Isogai, M., Katsuta, Y., et al. (2006) Large-Scale Fabrication of Ordered Nanoporous Alumina Films with Arbitrary Pore Intervals by Critical-Potential Anodization. Journal of the Electrochemical Society, 153, 384-391. http://dx.doi.org/10.1149/1.2218822

[8] Nielsch, K., Choi, J., Schwirn, K., Wehrspohn, R.B. and Gösele, U. (2002) Self-Ordering Regimes of Porous Alumina: The 10\% Porosity Rule. Nano Letters, 2, 677-680. http://dx.doi.org/10.1021/nl025537k

[9] Li, A.P., Müller, F., Birner, A., Nielsch, K. and Gösele, U. (1998) Hexagonal Pore Arrays with a 50-420 nm Interpore Distance Formed by Selforganization in Anodic Alumina. Journal of Applied Physics, 84, 6023-6026. http://dx.doi.org/10.1063/1.368911

[10] Li, A.P., Müller, F. and Gösele, U. (2000) Polycrystalline and Monocrystalline Pore Arrays with Large Interpore Distance in Anodic Alumina. Electrochemical and Solid-State Letters, 3, 131-134. http://dx.doi.org/10.1149/1.1390979

[11] Yan, J., Rao, G.V.R., Barela, M., Brevnov, D.A., Jiang, Y., et al. (2003) Growth of Patterned Nanopore Arrays of Anodic Aluminum Oxide. Advanced Materials, 15, 2015-2018. http://dx.doi.org/10.1002/adma.200305360

[12] Yin, A.J., Li, J., Jian, W., Bennett, A.J. and Xu, J.M. (2001) Fabrication of Highly Ordered Metallic Nanowire Arrays by Electrodeposition. Applied Physics Letters, 79, 1039-1041. http://dx.doi.org/10.1063/1.1389765

[13] Nielsch, K., Müller, F., Li, A.-P. and Gösele, U. (2000) Uniform Nickel Deposition into Ordered Alumina Pores by Pulsed Electrodeposition. Advanced Materials, 12, 582-586. http://dx.doi.org/10.1002/(SICI)1521-4095(200004)12:8<582::AID-ADMA582>3.0.CO;2-3

[14] Kim, Y.-H., Han, Y.-H., Lee, H.-J. and Lee, H.-B. (2008) High Density Silver Nanowire Arrays Using Self-Ordered Anodic Aluminum Oxide (AAO) Membrane. Journal of the Korean Ceramic Society, 45, 191-195. http://dx.doi.org/10.4191/KCERS.2008.45.4.191

[15] Masuda, H. and Satoh, M. (1996) Fabrication of Gold Nanodot Array Using Anodic Porous Alumina as an Evaporation Mask. Japanese Journal of Applied Physics, Part 2: Letters, 35, L126-L129. http://dx.doi.org/10.1143/JJAP.35.L126

[16] Han, C.Y., Willing, G.A., Xiao, Z.L. and Hau Wang, H. (2007) Control of the Anodic Aluminum Oxide Barrier Layer Opening Process by Wet Chemical Etching. Langmuir, 23, 1564-1568. http://dx.doi.org/10.1021/la060190c

[17] Gong, J., Butler, W.H. and Zangari, G. (2010) Tailoring Morphology in Free-Standing Anodic Aluminium Oxide: Control of Barrier Layer Opening Down to the Sub-10 nm Diameter. Nanoscale, 2, 778-785. http://dx.doi.org/10.1039/c0nr00055h

[18] Xu, T., Zangari, G. and Metzger, R.M. (2002) Periodic Holes with 10 nm Diameter Produced by Grazing Ar+ Milling of the Barrier Layer in Hexagonally Ordered Nanoporous Alumina. Nano Letters, 2, 37-41. http://dx.doi.org/10.1021/nl010075g

[19] Xu, T.T., Piner, R.D. and Ruoff, R. (2003) An Improved Method to Strip Aluminum from Porous Anodic Alumina Films. Langmuir, 19, 1443-1445. 